\title{
RESEARCH
}

Open Access

\section{Clinical profile of Plasmodium falciparum and Plasmodium vivax infections in low and unstable malaria transmission settings of Colombia}

\author{
Myriam Arévalo-Herrera ${ }^{1,2^{*}}$, Mary Lopez-Perez ${ }^{1}$, Luz Medina ${ }^{3}$, Alberto Moreno ${ }^{4,5}$, Juan B Gutierrez ${ }^{6}$ and Sócrates Herrera ${ }^{1}$
}

\begin{abstract}
Background: Malaria transmission in Latin America is generally hypoendemic and unstable, with Plasmodium vivax as the most prevalent species. However, only a few studies have been carried out in areas with low and unstable transmission, whereas the clinical profile of malaria has been broadly described in hyperendemic areas. The pattern of clinical manifestations and laboratory findings in low to moderate endemic areas of Colombia is reported here.

Methods: A passive surveillance study was conducted between 2011 and 2013 involving 1,328 patients with Plasmodium falciparum, P. vivax or mixed malaria infections attending malaria points-of-care of four malaria endemic-areas with distinct transmission intensities and parasite distribution. Trained physicians recorded clinical symptoms and signs as well as socio-demographic characteristics of study participants. Haematological, biochemical and urine tests were performed at the time of diagnosis.

Results: Out of 1,328 cases, 673 (50.7\%) were caused by P. vivax; 650 (48.9\%) were due to P. falciparum; and five $(0.4 \%)$ patients had mixed infections (P. falciparum/P. vivax). Most patients (92.5\%) presented with uncomplicated malaria characterized by fever, chills, headache, sweating, myalgia/arthralgia and parasitaemia $\leq 20,000$ parasites $/ \mu \mathrm{L}$. Fever, tachycardia, pallor and abdominal pain on palpation were more frequent in $P$. falciparum patients, whereas mild hepatomegaly and splenomegaly were mostly observed with $P$. vivax. Non-severe anaemia ( $\mathrm{Hb} 7.0-10.9 \mathrm{~g} / \mathrm{dL}$ ) was observed in $20 \%$ of the subjects, whereas severe anaemia $(\mathrm{Hb}<7.0 \mathrm{~g} / \mathrm{dL})$ was present in four patients. Half of the patients presented thrombocytopaenia regardless of parasite species. Leukopaenia, neutrophilia and monocytosis were frequently observed in patients infected with $P$. falciparum. Mild-to-moderate biochemical alterations were present in $\sim 25 \%$ of the patients, particularly abnormal bilirubin in those with $P$. falciparum and abnormal transaminases in $P$. vivax malaria patients. Proteinuria was present in $\sim 50 \%$ of the patients regardless of parasite species, whereas haemoglobinuria was more common in P. vivax infections. Only $7.5 \%$ of the cases were classified as clinically severe malaria, caused by both P. vivax and P. falciparum.
\end{abstract}

Conclusions: The high prevalence of uncomplicated malaria associated with moderate parasitaemia suggests the importance of timely diagnosis and effective treatment and encourages new activities to further decrease complicated malaria cases and mortality.

Keywords: Clinical profile, Plasmodium falciparum, Plasmodium vivax, Malaria, Colombia

\footnotetext{
* Correspondence: marevalo@inmuno.org

${ }^{1}$ Caucaseco Scientific Research Center, Cali, Colombia

${ }^{2}$ Faculty of Health, Universidad del Valle, Cali, Colombia

Full list of author information is available at the end of the article
} 


\section{Background}

Malaria remains a major public health problem in the developing world. In 2013, it caused an estimated 198 million clinical cases and 584,000 deaths [1]. The vast majority of these cases $(80 \%)$ and deaths $(90 \%)$ were caused by Plasmodium falciparum infections in sub-Saharan Africa, the region with the highest rates of transmission worldwide. High frequency of severe disease and fatal complications occur primarily during infancy and early childhood in this region $[1,2]$. Plasmodium vivax is the second most prevalent species that accounts for 75 to 85 million cases/year, corresponding to $>50 \%$ of malaria infections outside of Africa [3]. In Latin America, malaria transmission is typically classified as hypoendemic and unstable (annual parasite incidence, API $<0.1$ per 1,000 per year) for both Plasmodium species, with $\sim 145$ million inhabitants at risk of infection [1,4,5] and $~ 469,000$ cases reported in 2012, equivalent to $\sim 0.3 \%$ of the global burden. A total of 108 deaths reported in the region in 2012 correspond to $\sim 0.02 \%$ of the reported fatal malaria cases worldwide; the Amazon basin generating 90\% of the malaria cases [1]. Colombia accounts for $\sim 13 \%$ of the malaria cases [1,6], predominantly by $P$. vivax $(>70 \%)$, which co-exists with $P$. falciparum, with a remarkably different regional prevalence [6,7]. Such differences in prevalence are mainly due to the varied Duffy antigen expression in these populations $[8,9]$, and the clinical relapses due to $P$. vivax hypnozoite activation [10].

Human malaria has a broad clinical spectrum that includes asymptomatic infection, uncomplicated malaria, and complicated and lethal malaria cases [11]. This clinical spectrum depends on the complex interaction between the parasite, human host and environmental factors [12]. In temperate and sub-tropical regions of Asia and Latin America, residents of all ages have low levels of naturally acquired immunity, and thus typically present with acute or severe disease to mild and more chronic infections, particularly in adult men $[2,13]$. Most of the studies designed to better understand the association of the clinical profile of malaria with the parasite species have been carried out in areas of high malaria endemicity in Africa and Asia (e.g. Papua New Guinea and Indonesia), whereas studies carried out in low-tomoderate endemic areas around the world, particularly in Latin America, are scarce. Although Colombia is one of the major contributors to malarial morbidity and mortality in the region, limited information about the clinical profile and malaria severity is available [14-18], and much is based on retrospective studies of hospitalized subjects conducted before 2008 [19-21]. In those reports, severe anaemia, severe thrombocytopenia and hepatic failure were the most frequently reported complications [14-18,20,21].
During the last decade, Colombia has experienced a malaria-decreasing trend $[1,22]$, which could be explained by greater efforts to reduce disease burden, severity and mortality due to extensive use of insecticide bed-nets, and early diagnosis and prompt treatment. In addition, the low number of severe cases might also be due to the introduction of explicit indication of clinical signs of severe malaria in the Colombian Ministry of Health and Social Protection $(\mathrm{MoH})$ guidelines $[19,23,24]$. A recent study reported that at least for the regions studied, the malaria point-of-care (POC) were all located within an hour away from the patients households [25], which greatly contributed to early diagnosis and treatment with a consequent reduction of complicated cases and mortality $[7,19]$. It appears that early consultation reduces the contact of health care personnel in endemic areas with severe malaria cases, as most of these are likely to be treated in larger cities with greater health care infrastructure. Although this may benefit patients, it also leads to a dispersion of complicated cases with potential loss of valuable epidemiological information to accurately assess risk factors for morbidity and mortality. This study aimed at prospectively collecting information on the clinical profile of malaria from a large number of subjects acutely infected with $P$. falciparum and $P$. vivax residing in some of the highest malaria transmission regions in Colombia.

\section{Methods}

\section{Study design and ethical issues}

A passive surveillance study was conducted between 2011 and 2013 in four malaria outpatient clinics located in areas with distinct transmission intensity and parasite distribution. A total of 1,328 patients presenting malaria related symptoms were passively recruited at malaria POC. One site (Buenaventura) was excluded from the study since September 2012 because of the relatively low number of malaria cases. Patients with malaria infections confirmed by microscopic examination of Giemsa-stained thick blood smears (TBS) [26], and who received oral and written information about the study before enrollment, were asked to provide a written informed consent (IC) or an informed assent (IA) in the case of children $<18$ years/ old. Both documents were previously approved by the Institutional Review Board (IRB) affiliated with the MVDC (Malaria Vaccine and Drug Development Center, CECIV). A trained physician on the study research staff completed a standard clinical evaluation of all malaria symptomatic subjects. The local health provider treated all individuals as soon as the blood sample was drawn, using the national protocol for malaria treatment [23]. Patients infected with $P$. vivax were treated orally with curative doses of chloroquine $(25 \mathrm{mg} / \mathrm{kg}$ provided in three doses) and primaquine $(0.25 \mathrm{mg} / \mathrm{kg}$ daily for 14 days), whereas $P$. falciparum patients received artemether plus lumefantrine (six doses 
over three days). Each individual received a unique numerical code to simplify data collection and identification.

\section{Study sites}

Four defined endemic settings in Colombia were selected because of the relatively high level of malaria prevalence: Tierralta (Department of Córdoba); Quibdó (Department of Chocó); Tumaco (Department of Nariño); and Buenaventura (Department of Valle del Cauca) (Figure 1). Plasmodium vivax and P. falciparum are both transmitted in different proportions in these respective regions, which display an unstable endemic pattern [6,7]. Tierralta has a population of $\sim 90,000$ inhabitants with $44.4 \%$ living in rural areas. Most of inhabitants are described as mestizo ethnicity with a small Amerindian Emberá Katío indigenous community. The predominant malaria parasite species in this region is $P$. vivax ( $85 \%)$. Tumaco is a port city situated in the Pacific Coast close to the Ecuadorian border with a population of $\sim 160,000$ inhabitants, predominantly Afro-descendants with an Amerindian Awá indigenous community. The predominant malaria parasite species in the region is $P$. falciparum ( 79\%). Quibdo is situated on the Pacific Coast of Colombia close to the border with Panamá, with a population of $\sim 100,000$, mainly Afro-descendants. Most malaria cases in Quibdó are caused by P. falciparum ( 70\%). Buenaventura has a

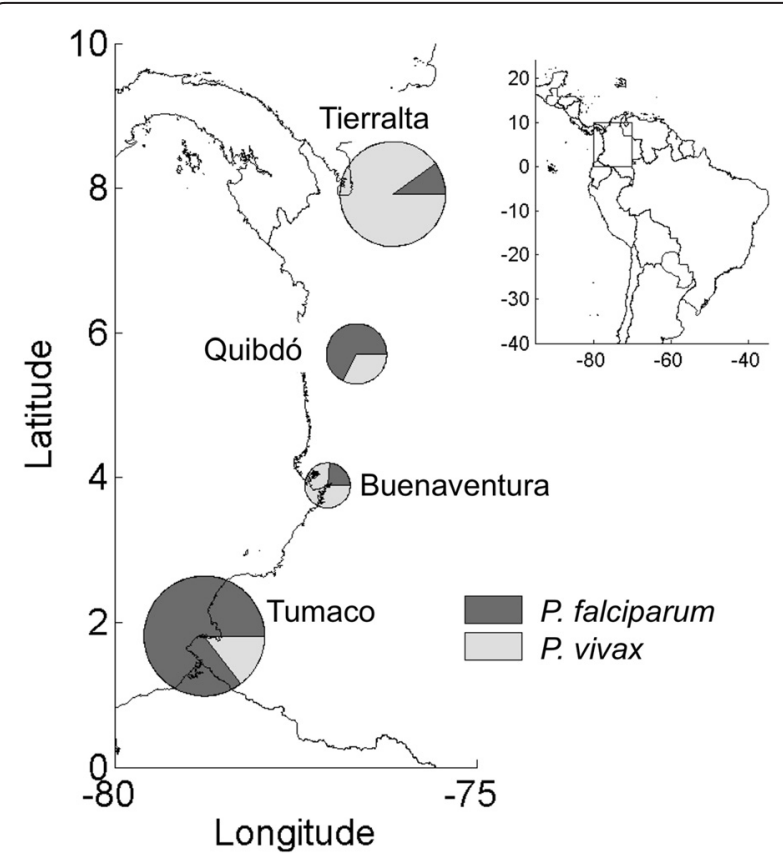

Figure 1 Distribution of malaria cases in the study areas. The charts display the proportion of Plasmodium species per site. P. vivax cases were more frequent in Tierralta (90\%) and Buenaventura (77\%), whereas $P$. falciparum infections were more prevalent in Quibdó (66\%) and Tumaco (85\%). population of 350,000 inhabitants with $>90 \%$ living in the urban area. Most of the inhabitants are Afro-descendants and mestizos; in this site $P$. vivax is the most prevalent malaria species $(\sim 75 \%)$.

\section{Clinical assessment}

Patients were classified as uncomplicated or severe malaria cases according to the WHO clinical and laboratory criteria [27] and the Colombian $\mathrm{MoH}$ guidelines [23]. The latter are more conservative in some definitions based on previous evidence: anaemia $(\mathrm{Hb}<7 \mathrm{~g} / \mathrm{dL}$ in adults and children), renal dysfunction (serum creatinine $>1.5 \mathrm{mg} / \mathrm{dL})$, severe thrombocytopenia $(\leq 20,000$ platelets $/ \mu \mathrm{L})$ and hyperparasitaemia $(>50,000$ parasites/ $\mu \mathrm{L})$. Uncomplicated malaria was defined as a clinical malaria case: symptoms such fever $>38^{\circ} \mathrm{C}$, headache, chills and/or malaise and a positive TBS without severity criteria, regardless of parasite species. Severe malaria was defined as one or more of the clinical or laboratory parameters [27,23], regardless of the malaria parasite species. Clinical and parasitological signs of prognostic danger were recorded [24].

\section{Laboratory tests}

Whole blood (7-15 $\mathrm{mL}$ ) was drawn by venipuncture at the time of enrollment before anti-malarial treatment. Samples were collected into Vacutainer tubes containing either EDTA for plasma collection, or clot activator and gel for serum separation. Giemsa stained TBS [26] were examined by a trained malaria microscopists who determined parasite species and density, which were expressed in parasites $/ \mu \mathrm{L}$ after counting the number of parasites per 200 white blood cells (WBC); counts were normalized using the actual WBC counts for each patient. For quality control, $10 \%$ of TBS were re-examined by a second microscopist and all samples were confirmed by real-time quantitative PCR (RT-qPCR) as described elsewhere [28].

Complete blood cell counts were performed using an automated haematology analyzer (KX-21 N, Sysmex, Japan) and both urine dipstick and urine microscopic analyses were carried out at the local health facility. Sera for blood chemistry profiles were stored frozen and analysed using commercial kits at the central Asoclinic laboratory in Cali (non-endemic area). The following parameters were measured: haemoglobin (normal values 11.0-16.5 g/dL), haematocrit (normal value $35-50 \%$ ), creatinine (normal values $0.6-1.1 \mathrm{mg} / \mathrm{dL}$ in females, and 0.7 $1.4 \mathrm{mg} / \mathrm{dL}$ in males), blood urea nitrogen (BUN; normal values $7-21 \mathrm{mg} / \mathrm{dL}$ ), glycaemia (normal values $60-110 \mathrm{mg} /$ $\mathrm{dL}$ ), total bilirubin ( $\mathrm{TB}$; normal values $\leq 1.0 \mathrm{mg} / \mathrm{dL}$ ), direct bilirubin (DB; normal values $\leq 0.25 \mathrm{mg} / \mathrm{dL}$ ), alanine aminotransferase (ALT; normal values $\leq 31 \mathrm{U} / \mathrm{L}$ in females, and $\leq$ $40 \mathrm{U} / \mathrm{L}$ in males), aspartate aminotransferase (AST; normal values $\leq 32 \mathrm{U} / \mathrm{L}$ in females and $\leq 38 \mathrm{U} / \mathrm{L}$ in males). 


\section{Statistical analysis}

Study data were collected and managed using REDCap (Nashville, Tennessee, USA) with electronic data capture tools [29]. Data were analysed with the statistical software MATLAB $^{\odot}$ 2013a (The MathWorks, Inc., Natick, Massachusetts, USA). Nominal variables were analysed using descriptive statistics. The Mann-Whitney $U$ test was used to compare two groups. Spearman's rank correlation $\left(\mathrm{r}_{\mathrm{s}}\right)$ was used to assess the correlation between numeric variables. Chi-square or Fisher's exact test were used to compare proportion differences. A p-value $<0.05$ was considered statistically significant.

\section{Results}

\section{Demographic data and malaria history}

A total of 1,328 subjects ( $55.4 \%$ male) with acute malaria were enrolled in four endemic sites between 2011 and 2013. A total of 563 patients were recruited in Tierralta, 549 in Tumaco, 177 in Quibdó, and 39 in Buenaventura (Figure 1). Plasmodium species distribution was statistically different in the study sites; however the overall distribution indicated a total of 673 (50.7\%) participants presenting with $P$. vivax malaria, and 650 (48.9\%) with $P$. falciparum infections. Mixed malaria infections $(P$. vivax/P. falciparum) were found in five cases $(0.4 \%)$; four in Quibdó and one in Buenaventura.

Patients had a mean age of 26 years (median 21 years; IQR $14-36$ years); children $\leq 15$ years of age (25.5\%) were mainly infected with $P$. vivax, whereas young adults between 16 and 30 years of age (40.3\%) were infected with either $P$. vivax or $P$. falciparum (Figure 2). Some differences in race and occupation were observed between $P$. falciparum and $P$. vivax infected patients. Tumaco malaria cases were mostly due to $P$. falciparum

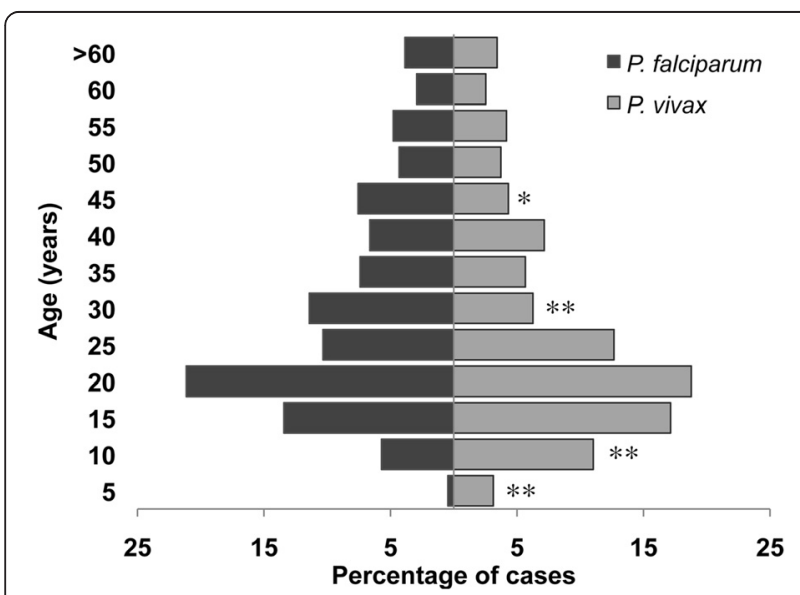

Figure 2 Prevalence and parasite species distribution according to age. Percentage of subjects infected with either $P$. falciparum or $P$. vivax parasites at each stratified age group are shown. Statistical differences between $P$. falciparum and $P$. vivax infections were calculated using the Chi-square test. ${ }^{*} p$ value $<0.05,{ }^{* *} p$ value $<0.01$. where population is mainly Afro-descendent dedicated to fishing, whereas in Tierralta where population is mainly mestizo farmers, most cases were induced by P. vivax (Table 1, Figure 1). Differences in some demographic and epidemiological variables were observed between $P$. falciparum and $P$. vivax infected patients (Table 1). Patients presenting mixed infections $(n=5$, 3 males) were 8 to 37 years old and reported a median of 8 days of illness (range 3 to 17 days).

Of the entire study population, 677 subjects (51.0\%) self-reported to have experienced previous lifetime malaria episodes with a median of two previous episodes. A majority of patients $(n=425 ; 62.8 \%)$ reported having suffered malaria within the last six months prior to current episode, and $6.2 \%$ of these during the last month, while $2.3 \%$ reported $\geq 10$ lifetime episodes.

A total of 359/677 (53\%) patients who reported previous malaria episodes, declared to have received antimalarial chemotherapy for the last malaria episode, and most $(\sim 80 \%)$ reported taking the complete treatment regimen. Overall, patients presented at health facilities promptly for malaria diagnosis regardless of parasite species, although a few patients $(n=42)$ reported $>15$ days of illness. A low proportion of patients $(n=77)$ self-reported concomitant clinical entities such as chronic cardiovascular diseases (20/77), gastrointestinal disorders (13/77), chronic respiratory diseases $(11 / 77)$, diabetes $(2 / 77)$ and others.

Most patients (97\%) presented with low-to-moderate parasitaemia $(\leq 20,000$ parasites $/ \mu \mathrm{L})$, with the median parasitaemia significantly higher for $P$. vivax $(3,314$ parasites/ $\mu \mathrm{L}$; IQR $1,486-6,521)$ than for $P$. falciparum $(1,482$ parasites/ $\mu \mathrm{L}$; IQR 602-3,782).

\section{Uncomplicated malaria Clinical findings}

A total of 1,229 individuals (92.5\%) were classified as uncomplicated malaria, and $>90 \%$ reported with the classical malaria triad of fever, chills and sweating, together with headache (Table 2, Figure 3). Overall, symptoms presented with a similar distribution for both parasite species (Figure 3A). Most frequent clinical signs on physical examination are shown in Figure 3B. Fever (axillary temperature $>38^{\circ} \mathrm{C}$ ) was significantly more frequent in $P$. falciparum cases, whereas pallor was more frequent in $P$. vivax infected patients (Figure 3B). Uncommon symptoms, such as vomiting (23\%), cough (15\%) and diarrhea (8\%), were mostly reported in $P$. vivax patients. Hyperpyrexia $(8.1 \%)$ and hypothermia $(1.3 \%)$ were also observed. Ten patients presented with hepatosplenomegaly (ranged 1-3 cm below the costal margin) all with $P$. vivax infections; one had a mixed infection. None presented with hepatic dysfunction, although mild alterations in total bilirubin and hepatic enzymes were observed. 
Table 1 Demographic data and malaria history per parasite species

\begin{tabular}{|c|c|c|c|c|c|c|}
\hline & & \multicolumn{2}{|c|}{ P. falciparum $(n=650)$} & \multicolumn{2}{|c|}{ P. vivax $(n=673)$} & \multirow[t]{2}{*}{$\mathrm{p}$ value } \\
\hline & & Median & $\mathrm{IQR}^{a}$ & Median & IQR & \\
\hline Age (years) & & 24 & $16-38$ & 19 & $12-33$ & $<0.001$ \\
\hline Time of residence (years) & & 4 & $1-4$ & 4 & $3-4$ & 0.365 \\
\hline Previous malaria episodes & & 2 & $1-3$ & 3 & $1-5$ & $<0.001$ \\
\hline Days of illness & & 4 & $2-6$ & 4 & $3-5$ & 0.689 \\
\hline Frequencies & & $\mathbf{n}$ & $\%$ & $\mathbf{n}$ & $\%$ & p value ${ }^{c}$ \\
\hline Male & & 334 & 51.4 & 399 & 59.3 & 0.004 \\
\hline \multicolumn{7}{|l|}{ Race } \\
\hline & Afro-descendant & 526 & 80.9 & 230 & 34.2 & $<0.001$ \\
\hline & Mestizo & 91 & 14.0 & 415 & 61.7 & $<0.001$ \\
\hline & Indigenous & 28 & 4.3 & 22 & 3.3 & 0.322 \\
\hline \multicolumn{7}{|l|}{ Occupation } \\
\hline & Student & 237 & 36.5 & 226 & 33.6 & 0.272 \\
\hline & Housewife & 177 & 27.2 & 150 & 22.3 & 0.037 \\
\hline & Farmer & 47 & 7.2 & 141 & 21.0 & $<0.001$ \\
\hline & Other $^{d}$ & 189 & 29.1 & 155 & 23 & 0.251 \\
\hline Previous malaria episodes (YES) & & 222 & 34.2 & 452 & 67.2 & $<0.001$ \\
\hline Malaria episodes in the last year & & 65 & 29.2 & 232 & 51.3 & $<0.001$ \\
\hline Anti-malarial treatment ${ }^{e}$ & & 43 & 19.4 & 314 & 69.5 & $<0.001$ \\
\hline
\end{tabular}

${ }^{a}$ IQR: interquartile range. ${ }^{b} \mathrm{p}$ value using Mann-Whitney test between $P$. falciparum and $P$. vivax. ${ }^{c} \mathrm{p}$ value using the Chi-square test between $P$. falciparum and $P$. vivax. ${ }^{d}$ fisherman, miner, timber exploitation, other. ${ }^{e}$ treatment for the last malaria episode. Most frequent and significant data are highlighted in bold.

\section{Haematological findings}

Thrombocytopenia was rather common $(48.6 \%)$ although in most cases it was mild-to-moderate $(50,000$ to $150,000$ platelets $/ \mu \mathrm{L})$; only 20 patients $(1.5 \%)$ had low platelets levels $(13,000$ to 50,000 platelets $/ \mu \mathrm{L})$, with a negative correlation between platelets count and parasitaemia $\left(\mathrm{r}_{\mathrm{s}}=-0.167 ; \mathrm{p}<0.0001\right)$. Anaemia presented in $19.7 \%$ of patients, mostly $\leq 15$ years of age $(60.1 \%$; $\mathrm{p}<0.0001)$ with only three patients $(0.2 \%)$ displaying severe anaemia. Neither thrombocytopenia nor anaemia was associated with parasite species, and more patients infected with $P$. vivax had lower erythrocyte mean corpuscular volumes $(16.3 \%$ vs $9.9 \%$ ) and mean corpuscular haemoglobin concentration $(54.0 \%$ vs $6.9 \%)$ than those infected with P. falciparum. Leukocyte alterations, including leukopaenia (27.3\%), neutrophilia (60.8\%) and monocytosis (21.3\%) were more common in $P$. falciparum infections $(\mathrm{p}<0.01)$ and displayed a positive correlation between leukocyte count and parasitaemia $\left(r_{s}=0.348 ; \mathrm{p}<0.0001\right)$, but none presented with severe deviations.

\section{Clinical biochemical findings}

Blood chemistry parameters of hepatic and renal function were normal in $>60 \%$ of the patients. Mild-to-moderate alterations in bilirubin levels [TB (11\%), DB (16\%)] were found mainly in patients infected with $P$. vivax $(\mathrm{p}<0.01)$, with a positive correlation between $\mathrm{TB}$ levels and parasitaemia $\left(\mathrm{r}_{\mathrm{s}}=0.155 ; \mathrm{p}<0.0001\right)$. In contrast, abnormal transaminases (ALT and AST) from mild-to-moderate levels were more frequent in $P$. falciparum patients than P. vivax $(14 \%$ vs $8 \%$; $<$ < 0.05$)$ (Table 3$)$. Renal function parameters showed mild alterations in creatinine (26\%) and

Table 2 Clinical profile of all patients studied

\begin{tabular}{|c|c|c|c|c|c|c|}
\hline \multirow[t]{2}{*}{ Classification } & & \multirow{2}{*}{$\begin{array}{l}\text { P. falciparum } \\
\text { n }\end{array}$} & \multirow{2}{*}{$\begin{array}{l}\mathrm{n}=650 \\
\%\end{array}$} & \multirow{2}{*}{$\begin{array}{l}\text { P. vivax } \\
\mathrm{n}\end{array}$} & \multirow{2}{*}{$\begin{array}{l}n=673 \\
\%\end{array}$} & \multirow[t]{2}{*}{ p value ${ }^{a}$} \\
\hline & & & & & & \\
\hline \multirow[t]{2}{*}{ Uncomplicated malaria } & & 529 & 81.4 & 566 & 84.1 & 0.191 \\
\hline & Warning signs & 68 & 10.5 & 61 & 9.1 & 0.392 \\
\hline \multicolumn{7}{|l|}{ Complicated malaria } \\
\hline & One complication & 43 & 6.6 & 42 & 6.2 & 0.781 \\
\hline & Two complications & 10 & 1.5 & 4 & 0.6 & 0.093 \\
\hline
\end{tabular}

${ }^{a} \mathrm{p}$ value using the Chi-square test between $P$. falciparum and $P$. vivax. 


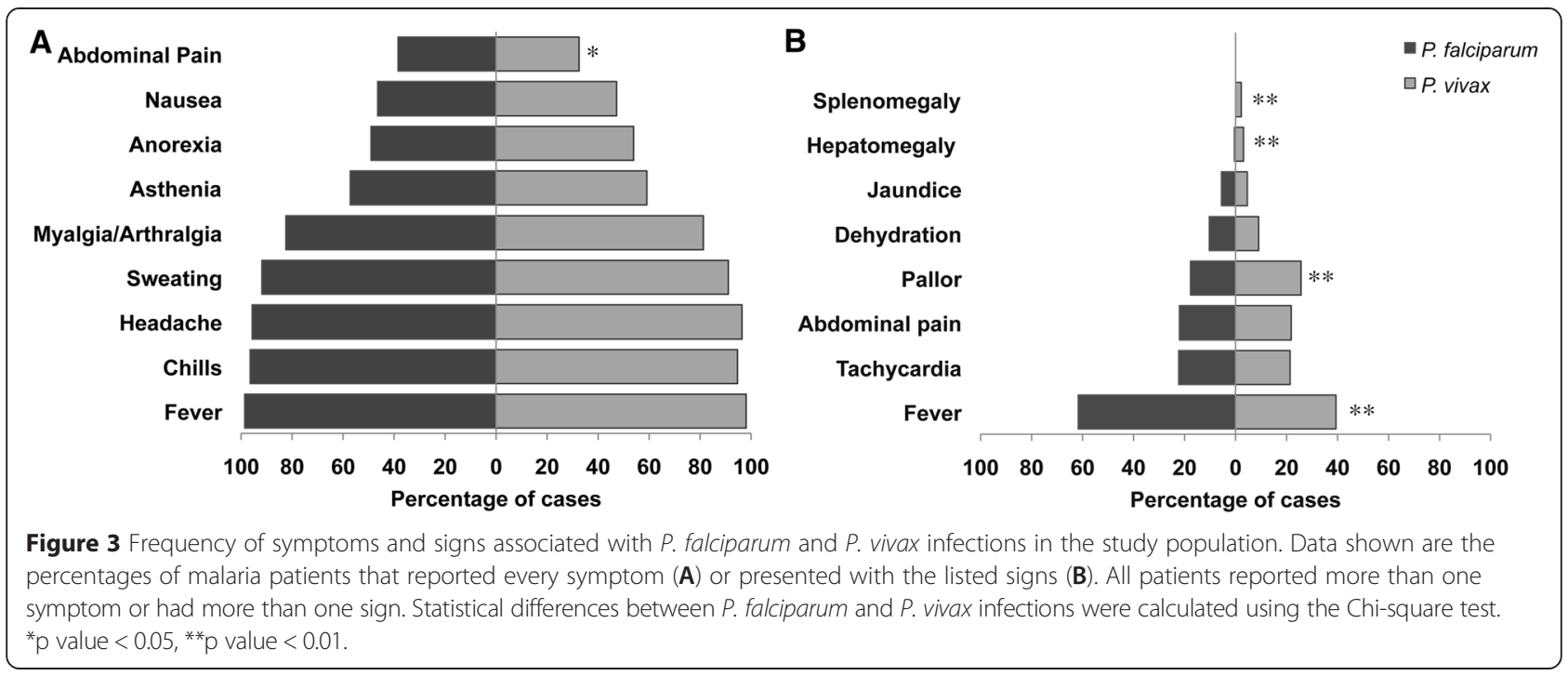

BUN (5\%), with similar distribution between parasites species. Proteinuria was observed in 54\% P. falciparum patients and $47 \%$ with $P$. $\operatorname{vivax}(\mathrm{p}=0.014)$, and it was associated with creatinine levels $>1.5 \mathrm{mg} / \mathrm{dL}(\mathrm{p}=0.013)$. Other significant alterations more frequently found in $P$. falciparum than in $P$. vivax-infected patients $(\mathrm{p}<0.001)$, were haematuria ( $26 \%$ vs $4 \%$ ), ketonuria ( $22 \%$ vs $12 \%$ ) and leukocyturia ( $17 \%$ vs $4 \%$ ), respectively. In contrast, haemoglobinuria was more frequently observed in $P$. vivax infections $(14 \%$ vs 4\%; $\mathrm{p}<0.001)$. Hypoglycaemia, ranging between 46 and $59 \mathrm{~g} / \mathrm{dL}$ was found only in four patients.

\section{Malaria with warning signs}

A total of 129/1,323 patients (9.8\%), excluding five with mixed infections, presented with one or more signs suggesting severe malaria development [24] (Table 4). Tachypnea in absence of fever was the most frequent. Twenty-four patients (1.8\%) presented with persistent vomiting (range 5 to 15 episodes), and six presented with signs of dehydration. Few patients $(14 / 1,323)$ had consciousness alteration including somnolence (11/14), lethargy or irritability and aggressiveness (3/14). A child (12 years old) presented with only one episode of generalized seizures $(<1 \mathrm{~min})$ without any other complication related to cerebral malaria.

Choluria (bilirubin in urine) was associated with $P$. falciparum infection, microscopic haemoglobinuria (Hbpositive dipstick) and proteinuria $(\mathrm{p}<0.010)$, suggesting an important renal involvement. Microscopic haematuria (>3 RBC) and hyperbilirubinaemia ( $\mathrm{TB}>3 \mathrm{mg} / \mathrm{dL}$ ) were also observed in $28 \%$ and $12 \%$ of patients, respectively, with choluria.

\section{Severe malaria}

A total of 99 patients (57\% male) with a mean age of 27 years (median 23 years; IQR 15-38 years) were classified with complicated malaria (Table 5). Fifty-four (4.1\%) of which required hospitalization because of their clinical condition. Thirteen of these patients presented with two complications simultaneously, one of which

Table 3 Clinical laboratory parameters

\begin{tabular}{|c|c|c|c|c|c|c|}
\hline \multirow[t]{3}{*}{ Laboratory parameters } & \multicolumn{2}{|c|}{ Uncomplicated malaria $(n=1225)$} & \multirow[t]{3}{*}{ p value ${ }^{b}$} & \multicolumn{2}{|c|}{ Severe malaria $(n=99)$} & \multirow[t]{3}{*}{$\mathrm{p}$ value } \\
\hline & \multicolumn{2}{|l|}{ Median $\left(\mathrm{IQR}^{a}\right)$} & & \multicolumn{2}{|l|}{ Median $\left(\mathrm{IQR}^{a}\right)$} & \\
\hline & P. falciparum & P. vivax & & P. falciparum & P. vivax & \\
\hline Haemoglobin (g/dL) & $12.5(11.2-13.6)$ & $12.7(11.3-14)$ & 0.024 & $12.8(11.5-13.8)$ & $12.8(10.9-14.2)$ & ns \\
\hline Platelets count $\left(\times 10^{3} / \mu \mathrm{L}\right)$ & $159(123.5-209)$ & $150(112-196.5)$ & 0.008 & $120(83-159)$ & $138(82-660)$ & ns \\
\hline Total bilirubin (mg/dL) & $0.6(0.3-0.9)$ & $0.7(0.4-1.1)$ & $<0.001$ & $1.0(0.3-2.5)$ & $1.0(0.5-3.4)$ & ns \\
\hline Direct bilirubin (mg/dL) & $0.17(0.08-0.27)$ & $0.18(0.10-0.32)$ & 0.002 & $0.25(0.10-0.98)$ & $0.32(0.18-0.52)$ & ns \\
\hline $\operatorname{ALT}(U / L)$ & $33(24-48)$ & $29(23-38)$ & $<0.001$ & $50(19-141)$ & $19(15-38)$ & 0.001 \\
\hline AST $(U / L)$ & $21(14-32)$ & $17(12-24)$ & $<0.001$ & $75(32-154)$ & $33(24-50)$ & 0.001 \\
\hline Creatinine (mg/dL) & $1.0(0.9-1.2)$ & $0.9(0.8-1.1)$ & $<0.001$ & $1.0(0.9-1.3)$ & $1.0(0.8-1.3)$ & ns \\
\hline
\end{tabular}

${ }^{a} \mathrm{QQR}$, interquartile range; ALT, Alanine aminotransferase; AST, aspartate aminotransferase; ns, not significant. ${ }^{b} \mathrm{p}$ value using the Mann-Whitney test between $P$. falciparum and $P$. vivax. Most frequent and significant data are highlighted in bold. 
Table 4 Warning signs of malaria in the study population

\begin{tabular}{|c|c|c|c|c|c|}
\hline \multirow[t]{2}{*}{ Sign } & \multicolumn{2}{|c|}{$\begin{array}{l}\text { P. falciparum } \\
(\mathrm{n}=68 / 650)\end{array}$} & \multicolumn{2}{|c|}{$\begin{array}{l}\text { P. vivax } \\
(\mathrm{n}=61 / 673)\end{array}$} & \multirow[t]{2}{*}{ p value ${ }^{a}$} \\
\hline & $\mathbf{n}$ & $\%$ & $\mathbf{n}$ & $\%$ & \\
\hline Tachypnea without fever & 17 & 2.6 & 30 & 4.5 & 0.076 \\
\hline Choluria & 30 & 4.6 & 13 & 1.9 & 0.007 \\
\hline Persistent vomiting & 11 & 1.7 & 13 & 1.9 & 0.744 \\
\hline Consciousness alteration & 9 & 1.4 & 5 & 0.8 & 0.254 \\
\hline Convulsions & 1 & 0.2 & 0 & 0 & NA \\
\hline
\end{tabular}

${ }^{a} \mathrm{p}$ value using the Chi-square test. NA, not applicable. Most frequent and significant data are highlighted in bold.

was hyperparasitaemic; a total of 41 patients had only one complication (Table 2). The most frequent complications in patients infected with either $P$. vivax or $P$. falciparum were: severe prostration $(\mathrm{n}=11)$, respiratory distress $(\mathrm{n}=4)$, hyperparasitaemia $(\mathrm{n}=4)$, abnormal spontaneous bleeding $(n=4)$, severe anaemia $(n=4)$, cardiogenic shock $(\mathrm{n}=1)$, and severe thrombocytopenia $(\mathrm{n}=1)$ as well as malaria warning signs including tachypnea in absence of fever and persistent vomiting or diarrhoea. Cerebral malaria was not observed. The remaining 45 patients were diagnosed and treated at the POC as uncomplicated malaria cases; however, when laboratory test were analysed, these revealed abnormalities indicating hepatic and renal dysfunctions according to the WHO and Colombian $\mathrm{MoH}$ guidelines [23,27]. However, whether some of these cases were diagnosed as complicated malaria in other health care institutions after the study enrollment, could not be confirmed.

Hepatic dysfunction with alteration in hepatic enzymes was more frequent in P. falciparum infections and observed only in adults. In contrast, haemoglobinuria detected by urine dipstick in absence of microscopic haematuria

Table 5 Frequency of complications in malaria patients

\begin{tabular}{|c|c|c|c|}
\hline Criteria & $\begin{array}{l}\text { P. falciparum } \\
\text { n (\%) }\end{array}$ & $\begin{array}{l}\text { P. vivax } \\
\mathrm{n}(\%)\end{array}$ & p value ${ }^{a}$ \\
\hline One complication & 43 & 42 & \\
\hline Hepatic dysfunction (TB >3 mg/dL) & $8(15.1)$ & $12(26.1)$ & ns \\
\hline Hepatic dysfunction (ALT > 120 U/L) & $12(22.6)$ & $2(4.3)$ & 0.001 \\
\hline Renal dysfunction (serum creatinine $>1.5 \mathrm{mg} / \mathrm{dL}$ or BUN $>40 \mathrm{mg} / \mathrm{dL}$ ) & $7(13.2)$ & $7(15.2)$ & ns \\
\hline Prostration & $6(11.3)$ & $5(10.9)$ & ns \\
\hline Haemoglobinuria (urine dipstick) & $1(1.9)$ & 9 (19.6) & 0.005 \\
\hline Respiratory distress & $1(1.9)$ & $3(6.5)$ & ns \\
\hline Hyperparasitaemia (>50,000 asexual parasites/ $\mu \mathrm{L}$ ) & $3(5.7)$ & $1(2.2)$ & ns \\
\hline Abnormal spontaneous bleeding & $3(5.7)$ & $0(0.0)$ & NA \\
\hline Severe anaemia $(\mathrm{Hb}<7 \mathrm{~g} / \mathrm{dL})$ & $1(1.9)$ & $2(4.3)$ & ns \\
\hline Cardiogenic shock/systolic dysfunction (SBP < 70 mm Hg) & $1(1.9)$ & $0(0.0)$ & NA \\
\hline Severe thrombocytopaenia ( $\leq 20,000$ platelets $/ \mu \mathrm{L}$ ) & $0(0.0)$ & $1(2.2)$ & NA \\
\hline More than one complication & 10 & 4 & \\
\hline \multicolumn{4}{|l|}{ Hyperparasitaemia plus } \\
\hline Severe thrombocytopaenia & $2(3.8)$ & $0(0.0)$ & NA \\
\hline Hepatic dysfunction & $1(1.9)$ & $1(2.2)$ & ns \\
\hline Renal dysfunction & $1(1.9)$ & $0(0.0)$ & NA \\
\hline Respiratory distress & $1(1.9)$ & $0(0.0)$ & NA \\
\hline Severe anaemia & $1(1.9)$ & $0(0.0)$ & NA \\
\hline Haemoglobinuria & $0(0.0)$ & $1(2.2)$ & NA \\
\hline \multicolumn{4}{|l|}{ Hepatic dysfunction plus } \\
\hline Prostration & $2(3.8)$ & $0(0.0)$ & NA \\
\hline Severe thrombocytopaenia & $1(2.2)$ & $0(0.0)$ & NA \\
\hline Renal dysfunction & $1(1.9)$ & $0(0.0)$ & NA \\
\hline \multicolumn{4}{|l|}{ Renal dysfunction plus } \\
\hline Prostration & $0(0.0)$ & $1(2.2)$ & NA \\
\hline Abnormal spontaneous bleeding & $1(1.9)$ & $0(0.0)$ & NA \\
\hline
\end{tabular}

$a_{\mathrm{p}}$ value using the Fisher's exact test. ALT, alanine aminotransferase; BUN, blood urea nitrogen; Hb, haemoglobin; NA, not applicable; ns, not significant; SBP, systolic blood pressure; TB, total bilirubin. Most frequent and significant data are highlighted in bold. 
was most frequent in adults infected by $P$. vivax. Renal dysfunction following the WHO criteria was not reported, but 14 patients met the Colombian $\mathrm{MOH}$ criteria (serum creatinine $>1.5 \mathrm{mg} / \mathrm{dL}$ ). This alteration was more frequent in adults than children $<15$ years of age $(18 \%$ vs $4 \%)$. In patients with complicated malaria anaemia (23.2\%), leukopenia (32.3\%), and thrombocytopenia (64.6\%) were common haematological alterations. Abnormal transaminases (ALT and AST) and hyperbilirubinaemia (TB > $1 \mathrm{mg} / \mathrm{dL}$ ) were also observed in $45.5 \%$ and $46.5 \%$ of patients, respectively (Table 2 ).

\section{Discussion}

As expected most malaria cases reported at the study sites had no clinical complications (92.5\%), which appear to correlate with the relatively low malaria transmission in the study areas [7], together with the early diagnosis and prompt treatment recently reported [30]. During the last decade the $\mathrm{MoH}$ has been expending considerable effort in an attempt to reduce the burden of infection and to eliminate malaria mortality. Additionally since 2005, the Global Fund for AIDS, tuberculosis and malaria (GFATM) has sponsored reinforcement of control activities in most endemic areas of Colombia, including the three study sites described here. This GFATM project appears to have significantly contributed to a reduction in malaria transmission and, therefore, to the low mortality reported, particularly in areas of easy access to health care $[19,22]$. The fact that it was found that $4.1 \%(54 / 1,328)$ of the malaria cases attending the POC required hospitalization even though most (41/54) displayed only a single severity criterion indicates a great underestimation in the number of complicated malaria cases in official reporting. Between 2011 and 2013 , a total of 1,322 of the $\sim 172,000$ malaria cases $(0.8 \%)$ reported in Colombia during that period were classified as complicated cases; 48 deaths ( $\sim 0.3$ per thousand) were considered malaria-related (National Surveillance Service of Colombia, SIVIGILA). This underestimation is also supported by the 45 individuals managed as uncomplicated malaria at the POC, who were later found to have clinical laboratory parameters compatible with the severe malaria case definition [23,27]. Patients attending the malaria POC are usually evaluated by community health workers, with low level of education, supervision and training, especially for clinical evaluation; whereas in this study a trained physician evaluated all patients.

Likewise, signs associated with severe clinical malaria emphasized in the $\mathrm{MoH}$ guidelines (warning signs) have significantly contributed to the early identification of potential malaria complications and to a decrease in the risk of severity and mortality. Warning signs reported here in 129 patients, including choluria, persistent vomiting and diarrhoea, tachypnea in absence of fever, hyperpyrexia and others, have been reported in previous clinical studies conducted in Colombia [16,24,31].

In contrast, in countries with higher malaria transmission such as Papua New Guinea [32] and Indonesia [33], the severe malaria incidence of individuals attending health facilities was $6.2 \%$ and $9 \%$, respectively. Studies about prevalence of severe malaria in Latin America are scarce and there have been no previous studies for the identification of severe cases at primary health facilities. Available information consists only of a series of case reports of hospitalized patients [20,21,34-37]. Interestingly, there has been a surge in studies reporting the contribution of $P$. vivax to severe malaria burden, challenging the idea that vivax malaria is 'benign' and not lethal [38,39]. Moreover, there have been recent reports on the role of $P$. vivax-infected erythrocytes adherence and pathophysiology of $P$. vivax [40-42]. In fact, several $P$. vivax severe cases there have been reported in Colombia [21], Brazil [34,35], Perú [36] and Venezuela [37], in agreement with this study.

Severe anaemia significantly contributes to malaria mortality [43]. As in previous reports [16,14,44], anaemia was only present as mild-to-moderate in $\sim 20 \%$ of the cases, and severe in only four patients. Because there is an inverse correlation between $\mathrm{Hb}$ levels and days of illness [45], results would support a short duration of infection and possibly the presence of iron deficiency as previously reported [46]. While most patients had a lowto-moderate parasitaemia, higher median parasitaemia was found in $P$. vivax-infected patients (3,314 parasites/ $\mu \mathrm{L}$ ) than in those infected with $P$. falciparum (1,482 parasites $/ \mu \mathrm{L}$ ). This finding is in agreement with previous reports in Colombia [16] and may be explained by the lower age, and consequently less cumulative malaria exposure in the group most infected by $P$. vivax (children $\leq$ 15 years/old), which had a significantly higher parasitaemia than the older age group.

Although thrombocytopaenia has been reported in up to $94 \%$ of acute malaria cases, frequently with severe intensity [47], here it was observed in less than half of the cases, with levels that did not represent a risk of spontaneous bleeding. Both thrombocytopaenia and anaemia are multifactorial but in both cases immunological factors have been considered important. The presence of anti-platelet antibodies as well as phagocyte-mediated platelet clearance have been previously described in Colombia and Brazil [48,49], however this hypothesis was not tested in this study.

Malaria-induced changes in the leukocyte populations are very diverse [50-54]; most commonly described alterations like mild-to-moderate leukopaenia, neutrophilia and monocytosis were transiently observed in this study. Leukocytosis, previously associated with severe disease and considered of poor prognosis [53], was not reported here. 
Because a significant proportion of the malaria cases $(40.3 \%)$ occurred in the economically active population (16-30 years of age), and lower prevalence (25.5\%) was found in children $\leq 15$ years of age, the selection of the study populations was not biased and it is speculated that malaria transmission may occur near to or inside households and schools where children $\leq 15$ years old spend most of their time. Although adult members of the family also spend a significant amount of time in the house and surrounding neighborhood, they did not appear to greatly contribute to malaria cases in this study, possibly harboring asymptomatic infections. A recent study in the same sites has indicated a prevalence of $\sim 6 \%$ of asymptomatic carriers. In addition, semi-immune young adult volunteers ( $\geq 18$ years old) from these sites, when exposed to experimental challenge with infectious P. vivax sporozoites developed significantly fewer symptoms than naïve volunteers [55]. In this context it could also be hypothesized that the relatively high prevalence of uncomplicated malaria in this study could be related to a significant level of clinical immunity, given the long-term residence of subjects in the endemic area, as was observed previously in Colombia [55]. In low transmission settings malaria clinical immunity develops significantly later; however, the previous study showed that five to 10 years of exposure at low transmission intensity could induce significant clinical immunity. In fact, $50 \%$ of patients reported living in the study areas $>5$ years with $51 \%$ reporting multiple previous malaria episodes. Furthermore, the almost equal proportion of $P$. vivax and $P$. falciparum cases appears to be due to the fact that most of the population where $P$. vivax is prevalent are mestizos, whereas $P$. falciparum was more prevalent in Afro-descendants with high prevalence of Duffy negative blood group $[8,9]$.

\section{Conclusions}

The present study showed a high prevalence of uncomplicated malaria together with moderate parasitaemia, which appear to be associated with low transmission intensity, early diagnosis and effective treatment, as well as to variable degrees of clinical immunity. Mild-to-moderate clinical and laboratory alterations specific to each parasite species were observed. Interestingly, at this transmission intensity patients infected with either parasite species appear to have a similar risk of developing the levels of severe malaria observed. It is likely that in regions with greater transmission intensity and other socio-economic conditions and more limited health infrastructure, P. falciparum patients would progress to severe and lethal cases at a greater rate as compared to $P$. vivax $[18,35,56]$. Here, no significant differences were observed in clinical and laboratory parameters for patients infected with either $P$. vivax or $P$. falciparum. A prospective study is currently ongoing aimed at a more detailed characterization of malaria complications in hospitalized patients and associated factors, which could contribute to improving $\mathrm{MoH}$ policies and strengthening the malaria information system in Colombia.

\section{Abbreviations}

ALT: Alanine aminotransferase; AST: Aspartate aminotransferase; BUN: Blood urea nitrogen; DB: Direct bilirubin; MoH: Ministry of Health; POC: Point-of-care; TB: Total bilirubin; WBC: White blood cells.

\section{Competing interests}

The authors declare that they have no competing interests.

\section{Authors' contributions}

MAH conceived of the study, its design, general coordination and manuscript comments. MLP and MAH analysed results and wrote the manuscript. JG and MLP performed the statistical analysis. LM carried out the laboratory tests. AM contributed to protocol design and provided comments on the manuscript. JBG was responsible of data management, quality assurance of data analysis and manuscript revision. SH was responsible for general direction of the study, discussion and manuscript comments. All authors read and approved the final manuscript.

\section{Acknowledgements}

The authors are very grateful to the participating patients and the local health personnel at all study sites, especially Tatiana Ahumada in Tierralta. We thank Nataly Jimenez for field coordination; Yoldy Benavides for assistance with statistical analysis in MATLAB; Andrés Vallejo, Nora Martínez, Daniel León, and Eliana Ortiz for technical support; and Alvaro Alvarez and Luis Castro, for implementation of formats in REDCap, data entry and all support in the data management. We also thank Malla Rao and Marcus Lacerda for critically reading the manuscript.

\section{Funding}

This work was sponsored by and conducted in sites corresponding to Centro Latino Americano de Investigación en Malaria (CLAIM) sponsored by NIAID/ICEMR (U19AI089702), Colciencias (360-2011, 458-2012, 719-2013) and the Colombian Presidential Agency of International Cooperation (045-2013). AM's involvement was supported by R21Al094402-01 and R21AI095718-01 from NIAID.

\section{Author details}

${ }^{1}$ Caucaseco Scientific Research Center, Cali, Colombia. ${ }^{2}$ Faculty of Health, Universidad del Valle, Cali, Colombia. ${ }^{3}$ Asoclinic Inmunología Ltda, Cali, Colombia. ${ }^{4}$ Emory University, Atlanta, GA, USA. ${ }^{5}$ Department of Medicine, Division of Infectious Diseases, Emory University, Atlanta, GA, USA. ${ }^{6}$ University of Georgia, Athens, GA, USA.

Received: 4 December 2014 Accepted: 4 April 2015

Published online: 11 April 2015

\section{References}

1. WHO. World Malaria Report 2014. Geneva: World Health Organization; 2014. p. 227

2. Feachem RG, Phillips AA, Hwang J, Cotter C, Wielgosz B, Greenwood BM, et al. Shrinking the malaria map: progress and prospects. Lancet. 2010;376:1566-78.

3. Mendis K, Sina BJ, Marchesini P, Carter R. The neglected burden of Plasmodium vivax malaria. Am J Trop Med Hyg. 2001;64(1-2 Suppl):97-106.

4. Guerra CA, Gikandi PW, Tatem AJ, Noor AM, Smith DL, Hay SI, et al. The limits and intensity of Plasmodium falciparum transmission: implications for malaria control and elimination worldwide. PLoS Med. 2008;5:e38.

5. Guerra CA, Howes RE, Patil AP, Gething PW, Van Boeckel TP, Temperley WH, et al. The international limits and population at risk of Plasmodium vivax transmission in 2009. PLoS Negl Trop Dis. 2010;4:e774.

6. Arevalo-Herrera M, Quinones ML, Guerra C, Cespedes N, Giron S, Ahumada $\mathrm{M}$, et al. Malaria in selected non-Amazonian countries of Latin America. Acta Trop. 2012;121:303-14. 
7. Rodriguez JC, Uribe GA, Araujo RM, Narvaez PC, Valencia SH. Epidemiology and control of malaria in Colombia. Mem Inst Oswaldo Cruz. 2011;106 Suppl 1:114-22

8. Herrera S, Gomez A, Vera O, Vergara J, Valderrama-Aguirre A, Maestre A, et al. Antibody response to Plasmodium vivax antigens in Fy-negative individuals from the Colombian Pacific coast. Am J Trop Med Hyg. 2005;73(5 Suppl):44-9.

9. Gonzalez LM, Vega J, Ramirez J, Bedoya G, Carmona-Fonseca J, Maestre A [Relationship between Duffy blood groups genotypes and malaria infection in different ethnic groups of Choco, Colombia] (in Spanish). Colomb Med. 2012;43:189-95.

10. White NJ. Determinants of relapse periodicity in Plasmodium vivax malaria. Malar J. 2011:10:297.

11. Grobusch MP, Kremsner PG. Uncomplicated Malaria. In: Sullivan DJ, Krishna S, editors. Malaria: Drugs, Disease and Post-genomic Biology. Current Topics in Microbiology and Immunology. Berlin: Springer Berlin Heidelberg; 2005. p. 81-104.

12. Maitland K, Marsh K. Pathophysiology of severe malaria in children. Acta Trop. 2004;90:131-40.

13. Shekalaghe S, Alifrangis M, Mwanziva C, Enevold A, Mwakalinga S, Mkali H, et al. Low density parasitaemia, red blood cell polymorphisms and Plasmodium falciparum specific immune responses in a low endemic area in northern Tanzania. BMC Infect Dis. 2009;9:69.

14. Echeverri M, Tobon A, Alvarez G, Carmona J, Blair S. Clinical and laboratory findings of Plasmodium vivax malaria in Colombia, 2001. Rev Inst Med Trop Sao Paulo. 2003:45:29-34.

15. Knudson A, Nicholls RS, Guerra AP, Sanchez R. [Clinical profiles of patients with uncomplicated Plasmodium falciparum malaria in northwestern Colombia] (in Spanish). Biomedica. 2007;27:581-93.

16. Tobon-Castano A, Giraldo-Castro C, Blair S. [Prognostic value of clinical and parasitological signs for severe malaria in patients from Colombia] (in Spanish). Biomedica. 2012;32 Suppl 1:79-94.

17. López ML, Arango EM, Arias LR, Carmona-Fonseca J, Blair S. [Intraleucocytic hemozoine as an indicator malaria complicated by Plasmodium falciparum] (in Spanish). Acta Med Colomb. 2004;29:80-7.

18. Tobon A, Giraldo C, Pineros-Jimenez JG, Arboleda M, Blair S, Carmona-Fonseca J. [The epidemiology of complicated falciparum malaria: case and controls study in Tumaco and Turbo, Colombia, 2003] (in Spanish). Rev Bras Epidemiol. 2006;9:283-96

19. Chaparro P, Padilla J. [Malaria mortality in Colombia, 1979-2008] (in Spanish). Biomedica. 2012;32 Suppl 1:95-105.

20. Gonzalez LM, Guzman M, Carmona J, Lopera T, Blair S. [Clinical and epidemiologic characteristics of 291 hospitalized patients for malaria in Medellin (Colombia)] (in Spanish). Acta Med Colomb. 2000;25:163-70.

21. Arboleda M, Perez MF, Fernandez D, Usuga LY, Meza M. [Clinical and laboratory profile of Plasmodium vivax malaria patients hospitalized in Apartado, Colombia] (in Spanish). Biomedica. 2012;32 Suppl 1:58-67.

22. Ramirez AP, Buitrago Jl, Gonzalez JP, Morales AH, Carrasquilla G. Frequency and tendency of malaria in Colombia, 1990 to 2011: a descriptive study. Malar J. 2014;13:202.

23. MinSalud. Ministerio de la Protección Social. Colombia. Guía de atención clínica de malaria. Colombia, Bogotá: Ministerio de la Protección Social; 2010. p. 132.

24. Tobon A. [Danger signs in the malaria patient] (in Spanish). Biomedica. 2009:29:320-9.

25. Forero DA, Chaparro PE, Vallejo AF, Benavides Y, Gutierrez JB, Arevalo-Herrera $\mathrm{M}$, et al. Knowledge, attitudes and practices of malaria in Colombia. Malar J. 2014;13:165.

26. Shute $P G$, Maryon M. An improved technique for staining malaria parasites with Giemsa stain. Arch Roum Pathol Exp Microbiol. 1963;22:887-94.

27. WHO. Severe falciparum malaria. World Health Organization, Communicable Diseases Cluster. Trans R Soc Trop Med Hyg. 2000;Suppl 1:S1-90.

28. Rougemont M, Van Saanen M, Sahli R, Hinrikson HP, Bille J, Jaton K. Detection of four Plasmodium species in blood from humans by $18 \mathrm{~S}$ rRNA gene subunit-based and species-specific real-time PCR assays. J Clin Microbiol. 2004:42:5636-43

29. Harris PA, Taylor R, Thielke R, Payne J, Gonzalez N, Conde JG. Research electronic data capture (REDCap)-a metadata-driven methodology and workflow process for providing translational research informatics support. J Biomed Inform. 2009:42:377-81.
30. Chaparro P, Padilla J, Vallejo AF, Herrera S. Characterization of a malaria outbreak in Colombia in 2010. Malar J. 2013;12:330.

31. Tobon Castano A, del Mar CA, Felipe Miranda A, Blair Trujillo S. [Dark urine and jaundice as warning signs in Plasmodium falciparum malaria in Colombia] (in Spanish). Rev Cubana Med Trop. 2010;62:28-35.

32. Genton B, D'Acremont V, Rare L, Baea K, Reeder JC, Alpers MP, et al. Plasmodium vivax and mixed infections are associated with severe malaria in children: a prospective cohort study from Papua New Guinea. PLoS Med. 2008;5:e127.

33. Barcus MJ, Basri H, Picarima H, Manyakori C, Sekartuti Elyazar I, Sekartuti El, et al. Demographic risk factors for severe and fatal vivax and falciparum malaria among hospital admissions in northeastern Indonesian Papua. Am J Trop Med Hyg. 2007;77:984-91.

34. Raposo CC, Santos JB, Santos GM, Goncalves Eda G, Silva AR. Plasmodium vivax malaria: related factors to severity in the State of Maranhao, Brazil. Rev Soc Bras Med Trop. 2013;46:67-72.

35. Alexandre MA, Ferreira CO, Siqueira AM, Magalhaes BL, Mourao MP, Lacerda MV, et al. Severe Plasmodium vivax malaria, Brazilian Amazon. Emerg Infect Dis. 2010;16:1611-4.

36. Quispe AM, Pozo E, Guerrero E, Durand S, Baldeviano GC, Edgel KA, et al. Plasmodium vivax hospitalizations in a monoendemic malaria region: severe vivax malaria? Am J Trop Med Hyg. 2014;91:11-7.

37. Rodriguez-Morales AJ, Sanchez E, Vargas M, Piccolo C, Colina R, Arria M. Anemia and thrombocytopenia in children with Plasmodium vivax malaria. J Trop Pediatr. 2006;52:49-51.

38. Naing C, Whittaker MA, Nyunt Wai V, Mak JW. Is Plasmodium vivax malaria a severe malaria?: a systematic review and meta-analysis. PLoS Negl Trop Dis. 2014:8:e3071.

39. Lacerda MV, Mourao MP, Alexandre MA, Siqueira AM, Magalhaes BM, Martinez-Espinosa FE, et al. Understanding the clinical spectrum of complicated Plasmodium vivax malaria: a systematic review on the contributions of the Brazilian literature. Malar J. 2012;11:12.

40. Lacerda MV, Fragoso SC, Alecrim MG, Alexandre MA, Magalhaes BM, Siqueira AM, et al. Postmortem characterization of patients with clinical diagnosis of Plasmodium vivax malaria: to what extent does this parasite kill? Clin Infect Dis. 2012;55:e67-74.

41. De las Salas B, Segura C, Pabon A, Lopes SC, Costa FT, Blair S. Adherence to human lung microvascular endothelial cells (HMVEC-L) of Plasmodium vivax isolates from Colombia. Malar J. 2013;12:347.

42. Costa FT, Lopes SC, Albrecht L, Ataide R, Siqueira AM, Souza RM, et al. On the pathogenesis of Plasmodium vivax malaria: perspectives from the Brazilian field. Int J Parasitol. 2012:42:1099-105.

43. Perkins DJ, Were T, Davenport GC, Kempaiah P, Hittner JB, Ong'echa JM Severe malarial anemia: innate immunity and pathogenesis. Int J Biol Sci. 2011;7:1427-42.

44. Caicedo O, Ramirez O, Mourao MP, Ziadec J, Perez P, Santos JB, et al. Comparative hematologic analysis of uncomplicated malaria in uniquely different regions of unstable transmission in Brazil and Colombia. Am J Trop Med Hyg. 2009:80:146-51.

45. Lopez-Perez M, Alvarez A, Gutierrez JB, Moreno A, Herrera S, Arevalo-Herrera M. Malaria-related anemia in patients from unstable transmission areas in Colombia. Am J Trop Med Hyg. 2015;92:294-301.

46. Blair S, Alvarez G, Campuzano G. [Relación entre anemia y malaria en una población rural de Colombia] (in Spanish). Bol Dir Malariol San Amb. 1997:37:7-2.

47. Lacerda MV, Mourao MP, Coelho HC, Santos JB. Thrombocytopenia in malaria: who cares? Mem Inst Oswaldo Cruz. 2011:106 Suppl 1:52-63.

48. Rios-Orrego A, Alvarez-Castillo T, Carmona-Fonseca J, Blair-Trujillo S. [Temporal evolution of platelets and anti-platelet antibodies in patients of endemic area with non complicated malaria] (in Spanish). An Med Interna. 2005;22:561-8.

49. Coelho HC, Lopes SC, Pimentel JP, Nogueira PA, Costa FT, Siqueira AM, et al. Thrombocytopenia in Plasmodium vivax malaria is related to platelets phagocytosis. PLoS One. 2013;8:e63410.

50. Rodrigues-da-Silva RN, Lima-Junior Jda C, e Fonseca Bde P, Antas PR, Baldez A, Storer FL, et al. Alterations in cytokines and haematological parameters during the acute and convalescent phases of Plasmodium falciparum and Plasmodium vivax infections. Mem Inst Oswaldo Cruz. 2014;109:154-62.

51. Gonzalez B, Rodulfo H, De Donato M, Berrizbeitia M, Gomez C, Gonzalez L. [Hematologic variations in patient with malaria caused by Plasmodium vivax before, during and after treatment] (in Spanish). Invest Clin. 2009;50:187-201. 
52. Taylor WR, Widjaja H, Basri H, Ohrt C, Taufik T, Tjitra E, et al. Changes in the total leukocyte and platelet counts in Papuan and non Papuan adults from northeast Papua infected with acute Plasmodium vivax or uncomplicated Plasmodium falciparum malaria. Malar J. 2008;7:259.

53. Ladhani S, Lowe B, Cole AO, Kowuondo K, Newton CR. Changes in white blood cells and platelets in children with falciparum malaria: relationship to disease outcome. Br J Haematol. 2002;119:839-47.

54. Pineros JG, Lopez ML, Carmona-Fonseca J, Blair S. [Liver and haematological safety of amodiaquine treatment in non-complicated falciparum malaria] (in Spanish). Colomb Med. 2006;37:258-65.

55. Arevalo-Herrera M, Forero-Pena DA, Rubiano K, Gomez-Hincapie J, Martinez NL, Lopez-Perez M, et al. Plasmodium vivax sporozoite challenge in malaria-naive and semi-immune Colombian volunteers. PLoS One. 2014;9:e99754.

56. Anstey NM, Russell B, Yeo TW, Price RN. The pathophysiology of vivax malaria. Trends Parasitol. 2009;25:220-7.

\section{Submit your next manuscript to BioMed Central and take full advantage of:}

- Convenient online submission

- Thorough peer review

- No space constraints or color figure charges

- Immediate publication on acceptance

- Inclusion in PubMed, CAS, Scopus and Google Scholar

- Research which is freely available for redistribution 